\title{
Engagement of private healthcare providers for case finding of tuberculosis and diabetes mellitus in Pakistan
}

Shifa Salman Habib1', Sana Rafiq ${ }^{1}$, Wafa Zehra Jamal ${ }^{1 *}$, Shaikh Muhammad Ayub ${ }^{1}$, Rashida Abbas Ferrand², Aamir Khan ${ }^{3}$ and Syed Mohammad Asad Zaidi ${ }^{1}$

\begin{abstract}
Background: The rising co-epidemic of tuberculosis (TB) and diabetes mellitus (DM) is a challenge for constrained health systems in low and middle-income countries. Diabetes is a known risk factor for tuberculosis and associated with poor tuberculosis treatment outcomes, while tuberculosis is associated with worsening glycemic control. We investigated the performance of bi-directional TB and DM case finding approaches through a private-sector engagement model in Karachi, Pakistan.

Methods: Between July 2016 and July 2018, private health care providers were engaged to generate referrals for bi-directional TB and DM screening at private diagnostic and treatment centers in Karachi, Pakistan. Individuals diagnosed with TB underwent glycated hemoglobin ( $\mathrm{HbA1c}$ ) testing at the time of anti-tuberculous treatment initiation and at three -month follow up stage. All individuals with a history of diabetes or random blood sugar of greater than $200 \mathrm{mg} / \mathrm{dl}$ were screened for TB using a chest X-ray and Xpert MTB/RIF.

Results: A total of 6312 persons with tuberculosis were tested on $\mathrm{HbA1C}$ at treatment initiation, of whom 1516 (24\%) were newly diagnosed with DM. About one third of those with HbA1c in the diabetic range $(\geq 6.5 \%)$ at baseline were found to have a normal HbA1c $(<5.7 \%)$ result at 3-month follow-up. A total of 3824 individuals with DM, of whom 2396 (63\%) were known cases and 1428 (37\%) were newly identified with random blood sugar > $200 \mathrm{mg} / \mathrm{dl}$, underwent chest $\mathrm{x}$-ray and Xpert MTB/RIF testing, with 321 (13.4\%) known and 54 (3.8\%) new diabetics respectively identified with tuberculosis.

Conclusion: This study demonstrates a high yield of TB and DM through bidirectional screening and the feasibility of engagement of private sector in finding missing cases of tuberculosis and diabetes. Given the high prevalence of undiagnosed DM in individuals with TB tuberculosis patients, there is a need to scale-up DM screening within TB programmes. Increased awareness of the high risk of TB among individuals with DM is needed among private health providers and screening for TB among diabetics should be strongly considered.
\end{abstract}

Keywords: Tuberculosis, Diabetes, Co-morbidity, Healthcare

\footnotetext{
*Correspondence: wafa.jamal@chshealthcare.org

${ }^{1}$ Community Health Solutions, 9th Floor, Al-Tijarah Building, Main Shahrah-e-Faisal, Karachi, Pakistan

Full list of author information is available at the end of the article
}

(c) The Author(s). 2020 Open Access This article is licensed under a Creative Commons Attribution 4.0 International License, which permits use, sharing, adaptation, distribution and reproduction in any medium or format, as long as you give appropriate credit to the original author(s) and the source, provide a link to the Creative Commons licence, and indicate if changes were made. The images or other third party material in this article are included in the article's Creative Commons licence, unless indicated otherwise in a credit line to the material. If material is not included in the article's Creative Commons licence and your intended use is not permitted by statutory regulation or exceeds the permitted use, you will need to obtain permission directly from the copyright holder. To view a copy of this licence, visit http://creativecommons.org/licenses/by/4.0/ The Creative Commons Public Domain Dedication waiver (http://creativecommons.org/publicdomain/zero/1.0/) applies to the data made available in this article, unless otherwise stated in a credit line to the data. 


\section{Background}

The global burden of Diabetes Mellitus (DM) has doubled from 1980 to 2017, posing a significant economic burden on health systems globally [1]. The International Diabetes Federation has estimated that the number of people living with DM worldwide will rise from 463 million in 2019 to 700 million by 2045 [2]. Tuberculosis (TB) remains the leading cause of death from a single infectious agent with an estimated 1.5 million deaths in 2018 [3].

There is increased recognition of the synergy between $\mathrm{DM}$ and TB $[4,5]$. Currently, an estimated 1 million people globally are present with TB-DM comorbidity, higher than the number of patients with TB-HIV coinfection [4]. DM increases the risk of developing TB three-fold and is associated with delayed sputum conversion, treatment failure, relapse and death [6]. TB in turn is associated with worsening glycemic control.

Based on available evidence, the International Union against TB and Lung Disease launched a Call to Action in 2014 that emphasized upon the significance of bidirectional screening and joint management of $\mathrm{TB}$ and DM [7]. However, implementation of these recommendations has been challenging in countries such as Pakistan where the private sector contributes to a majority of health services delivery. There have been very limited private-sector engagement initiatives that have addressed the dual burden of $\mathrm{TB}$ and $\mathrm{DM}$. We piloted a bidirectional screening project that developed a network of trained private-providers, linked to diagnostic and treatment centers for improved patient outcomes [8].

In this study we investigated the outcomes of the scale-up of a TB-DM bi-directional screening program in the private-sector in Karachi, Pakistan, modelled on the World Health Organization's (WHO) Collaborative Framework for care and control of tuberculosis and diabetes [9]. In addition to expanding the geographic coverage of the program, our current study also addresses the limitation of the pilot by using glycated hemoglobin (HbA1c) instead of random blood sugar (RBS) test as the diagnostic test for DM among individuals with TB.

\section{Methods}

\section{Study setting and design}

A retrospective cross sectional study in which, bidirectional screening for TB and DM was offered to clients attending private $\mathrm{TB}$ diagnostic and treatment centers "Sehatmand Zindagi (SZ) (healthy life) centers and community screening camps in Karachi, Pakistan between July 2016 and July 2018. Karachi is Pakistan's most populous city and the country's economic hub with an estimated $75 \%$ of all health services availed in the private sector [10]. Pakistan has the fourth highest burden of DM globally with a current estimated prevalence of
$17.1 \%$ in the adult population. An estimated 8.5 million adults are living with undiagnosed DM [2]. Pakistan is also ranked fifth among high tuberculosis burden countries with an estimated 36\% case notification gap [3].

The SZ centers, located in low middle income neighborhoods of Pakistan operate as a social business, providing free TB diagnostics, chest X-ray and Xpert MTB/ RIF, and treatment. Revenue is generated through other laboratory tests and radiology services. All TB cases are notified to the National TB Control Program (NTP). Each center has established linkages with other health providers in the vicinity including those in the informal health sector. The center has a dedicated team who engage private health providers and facilitate referral of individuals with presumptive TB to the centers. Clients are also able to self-refer to centers. Community based screening camps are conducted by trained community health workers employing mobile $\mathrm{X}$ - ray vans.

\section{Recruitment of individuals with TB for DM testing}

Individuals presenting at SZ Centers and screening camps with a previous history of $\mathrm{TB}$ or with signs and symptoms of $\mathrm{TB}$ were referred to the $\mathrm{TB}$ arm of screening where they were tested for $\mathrm{DM}$ if $\mathrm{TB}$ diagnosis was established. TB screening was conducted using digital chest $\mathrm{X}$ - rays with CAD4TB 5 (version 4.12.0) software for automated scoring Individuals with presumptive $\mathrm{TB}$ were defined as those with a threshold CAD4TB score of 70, who then submitted a sputum sample for Xpert MTB/RIF testing. A positive Xpert MTB/RIF testing result or a strong indication at clinical evaluation of the CXR and symptoms lead to the diagnosis of bacteriologically positive or clinical TB respectively. All individuals identified with TB underwent $\mathrm{HbA1c}$ testing at anti-tuberculous treatment (ATT) initiation. Those who gave consent also had a 3-month HbA1c follow up. According to the recommendation of 2009 American Diabetes Association (ADA), an $\mathrm{HbA} 1 \mathrm{c}<5.7 \%$ is classified as normal, $5.7-6.4 \%$ as pre-diabetes, and $\geq 6.5 \%$ as diabetes [11] Individuals who were diagnosed with diabetes at the SZ Center were counselled and referred to their general practitioner for further management.

\section{Recruitment of individuals with DM for TB testing}

Individuals attending the community camps and SZ Centers were verbally screened for history of diabetes. Those identified with DM or those presenting with signs and symptoms of DM were referred to the DM arm of screening where they were subsequently tested for TB if $\mathrm{DM}$ was diagnosed. If no known history of DM was found, they were offered a point of care glucose test. Individuals with an RBS $>200 \mathrm{mg} / \mathrm{dl}$ or history of diabetes, were tested on chest X-ray and Xpert MTB/RIF. 


\section{Data management and analysis}

We analyzed retrospective data of 10,136 Individuals who participated in the TB-DM bidirectional screening project funded by the World Diabetes Foundation. Under this project, data was recorded using a custombuilt mobile-phone application at community camps, A customized web-based laboratory management system (LMS) software was used to book tests and enter screening data at the centers. Both the mobile and web-based applications were integrated with the Central Management Information System with auto generated reports to track key project metrics. The data recording and reporting systems included several data validation checks to ensure data-accuracy. Field supervisors and project management staff were responsible for overall datavalidation and accuracy including reporting to the NTP. Baseline characteristics of participants were described using means and medians and the prevalence of DM and TB were calculated. The association of outcomes (DM and $\mathrm{TB}$ ) with a prior defined factor was explored using logistic regression. A comparative frequency analysis was conducted for $\mathrm{HbA1c}$ values at baseline and after 3 months of ATT for a subset of TB patients. All data was analyzed using Stata version 13.0 (StataCorp, Texas, USA).

\section{Ethical approval and consent}

An ethical approval was deemed unnecessary for this study by The Institutional Review Board (IRB) at Interactive Research and Development (IRD) under the IRB exemption category 7 under 45 CFR 46.101(b). The IRB is registered with the U.S. Department of Health and Human Services (DHHS), Office for Human Research Protections (IRB\#00005148). A Verbal consent was obtained from participants before conducting blood glucose, HbA1c and Xpert MTB/RIF tests. This study was part of a larger study (IRB approval number IRD_IRB_ 2016_08_001). De-identified data from the project was used for data analysis.

\section{Results}

Diabetes screening in individuals with TB using glycosylated hemoglobin (Hba1c) testing

A total of 5032 individuals had a positive Mycobacterium tuberculosis (MTB) result on Xpert MTB/RIF testing, while 5711 were identified with clinical TB (Fig. 1). Of these, 6312 were tested for DM using HbA1c. The

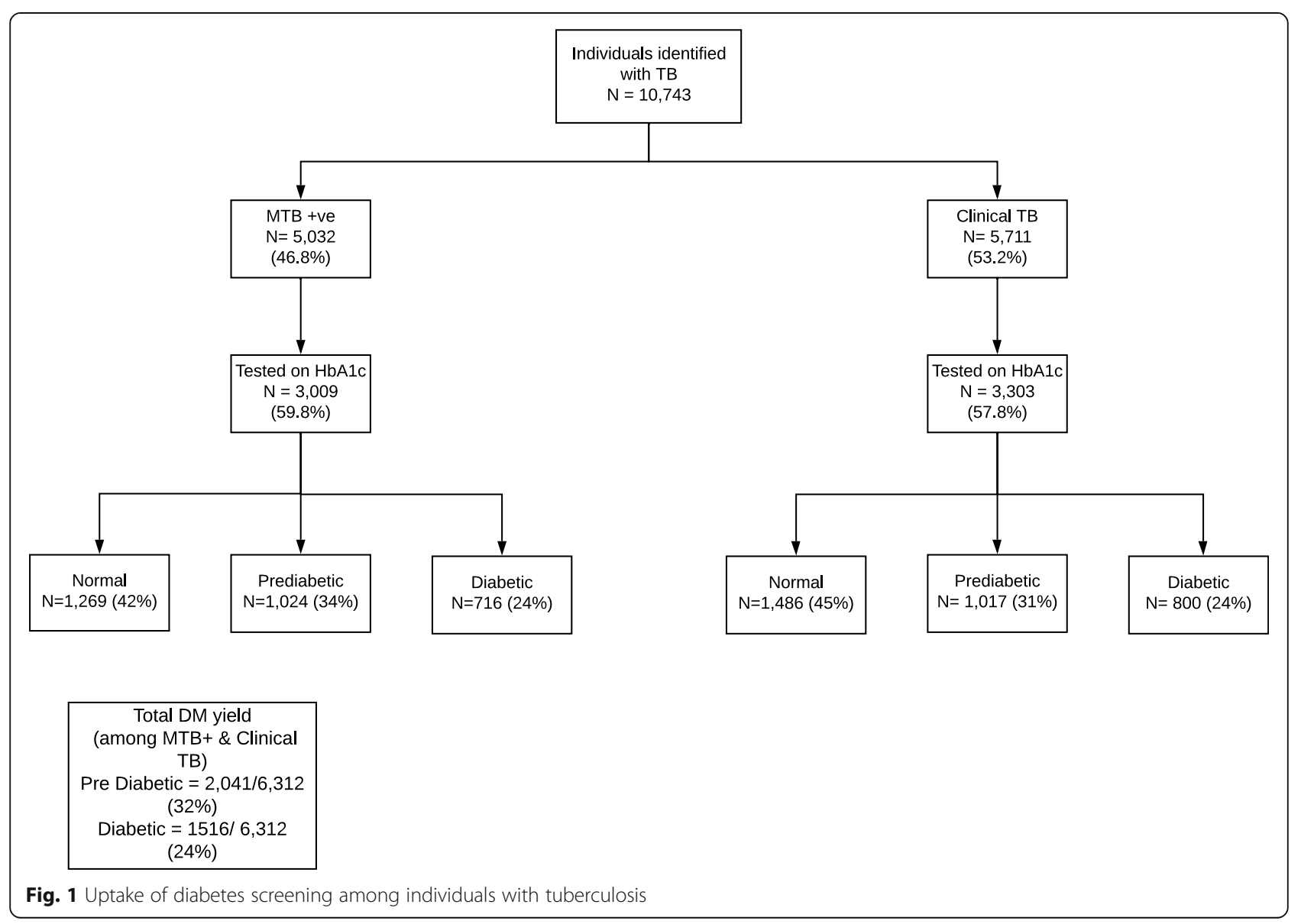


uptake of HbA1c testing was 59.8 and $57.8 \%$ in persons with bacteriologically positive and clinical TB respectively (Fig. 1). A majority (5093) were new TB cases. Among those screened for DM, 2041 (32\%) had prediabetes and 1516 (24\%) had newly diagnosed DM (Table 1). Of those newly diagnosed with DM $25 \%$ were male and 35\% were aged 40-59 years. The number needed to test (NNT) to make one DM diagnosis among individuals with TB was 4.16 (Table 1).

\section{Screening for TB among individuals with diabetes using Xpert MTB/RIF testing}

A total of 3824 individuals with DM underwent screening for $\mathrm{TB}$ at the SZ centers (Fig. 2). Of these, 1428 (37\%) had an RBS greater than $200 \mathrm{mg} / \mathrm{dl}$ on point of care testing and 2396 (63\%) had a known diagnosis of DM (Fig. 2). A majority were males and were aged 4059 years (Table 2). Among those referred from community camps and partner providers, 66.6 and 52.2\% respectively were known DM screened for TB whereas, 33.4 and $47.8 \%$ respectively were individuals with RBS > $200 \mathrm{mg} / \mathrm{dl}$. The uptake of Xpert MTB/RIF testing among individuals with $\mathrm{RBS}>200 \mathrm{mg} / \mathrm{dl}$ and known DM was 76 and $77 \%$ respectively (Fig. 2). Of the total individuals with TB detection, $85.6 \%$ were known cases of DM and $14.4 \%$ were individuals with an $\mathrm{RBS}>200 \mathrm{mg} / \mathrm{dl}$ who underwent Xpert testing (Table 2).

Known diabetes (OR 4.63, CI 3.21-6.66) was the strongest associated factor in final adjusted models for MTB detection (Table 3).
Follow-up HbA1c testing for individuals with TB

Among individuals with $\mathrm{TB}$ tested on $\mathrm{HbA} 1 \mathrm{C}$ at the ATT initiation, 1077 individuals also underwent followup HbA1c testing after 3 months and 514 (47.7\%) had an unchanged $\mathrm{HbA1c}$ range between the baseline and follow-up tests.

Among the 244 individuals with an $\mathrm{HbA1c} \geq 6.5 \%$ at baseline $64(26 \%)$ and $77(32 \%)$ had anHbA1c that dropped to $5.7-6.4$ and $<5.6 \%$ respectively at 3 months. Of the 331 persons with HbA1c in the pre-diabetes range at baseline, $148(44 \%)$ dropped to $<5.6 \%$ at 3 months. Of the 502 patients with $\mathrm{HbA} 1 \mathrm{c}<5.6 \%$ at baseline, 213 (42\%) had increased HbA1c $\geq 5.7 \%$ at followup (Fig. 3).

\section{Discussion}

This study describes findings from the first bidirectional screening programs for TB and DM carried out at scale in the private sector. This project was innovative in its use of CAD4TB for TB screening and the use of HbA1c for initial screening of DM among TB patients.

As in other studies [12-15], we report a high prevalence of TB among persons with DM. We also found that the odds of developing TB were nearly 4.5 times higher in persons with previously diagnosed DM compared to those who were newly diagnosed. It is possible that chronic hyperglycemia may be associated with an increased risk for developing TB. A recent study showed increased TB risk with duration of DM, with a median

Table 1 Baseline characteristics of individuals with TB tested for diabetes using HbA1c and numbers needed to test (NNT) to identify one case of diabetes

\begin{tabular}{|c|c|c|c|c|c|c|}
\hline & $\begin{array}{l}\text { Total TB Cases Tested for DM } \\
\text { n (\%) }\end{array}$ & $\begin{array}{l}\text { Normal } \\
\mathrm{n}(\%)\end{array}$ & $\begin{array}{l}\text { Pre-Diabetes } \\
\text { n (\%) }\end{array}$ & $\begin{array}{l}\text { Newly Diagnosed DM cases } \\
\text { n (\%) }\end{array}$ & $\mathrm{NNT}^{\ddagger}$ & $\boldsymbol{P}$ Value \\
\hline Total & 6312 & 2755 (44\%) & 2041 (32\%) & $1516(24 \%)$ & 4.16 & \\
\hline \multicolumn{7}{|l|}{ Sex } \\
\hline Male & 3347 & 1461 (43.7\%) & 1052 (31.4\%) & 834 (24.9\%) & 4.01 & 0.122 \\
\hline Female & 2965 & 1294 (43.6\%) & 989 (33.4\%) & $682(23 \%)$ & 4.35 & \\
\hline \multicolumn{7}{|l|}{ Age (years) } \\
\hline $15-20$ & 885 & 462 (52.2\%) & 318 (35.9\%) & 105 (11.9\%) & 8.43 & $<0.001$ \\
\hline 20-39 & 2407 & 1309 (54.4\%) & 739 (30.7\%) & 359 (14.9\%) & 6.70 & \\
\hline $40-59$ & 1750 & $593(33.9 \%)$ & $544(31.1 \%)$ & $613(35 \%)$ & 2.85 & \\
\hline$>60$ & 1270 & 391 (30.8\%) & 440 (34.6\%) & 439 (34.6\%) & 2.92 & \\
\hline \multicolumn{7}{|l|}{ TB diagnosis } \\
\hline MTB+ & 3009 & 1269 (42.2\%) & 1024 (34\%) & 716 (23.8\%) & 4.20 & 0.017 \\
\hline Clinically diagnosed & 3303 & 1486 (45\%) & 1017 (30.8\%) & $800(24.2 \%)$ & 4.13 & \\
\hline \multicolumn{7}{|l|}{ Past History of TB } \\
\hline No (New case) & 5093 & 2226 (43.7\%) & 1649 (32.4\%) & 1218 (23.9\%) & 4.18 & 0.927 \\
\hline Yes (Re-treatment & 1219 & $529(43.4 \%)$ & $392(32.2 \%)$ & $298(24.4 \%)$ & 4.09 & \\
\hline
\end{tabular}




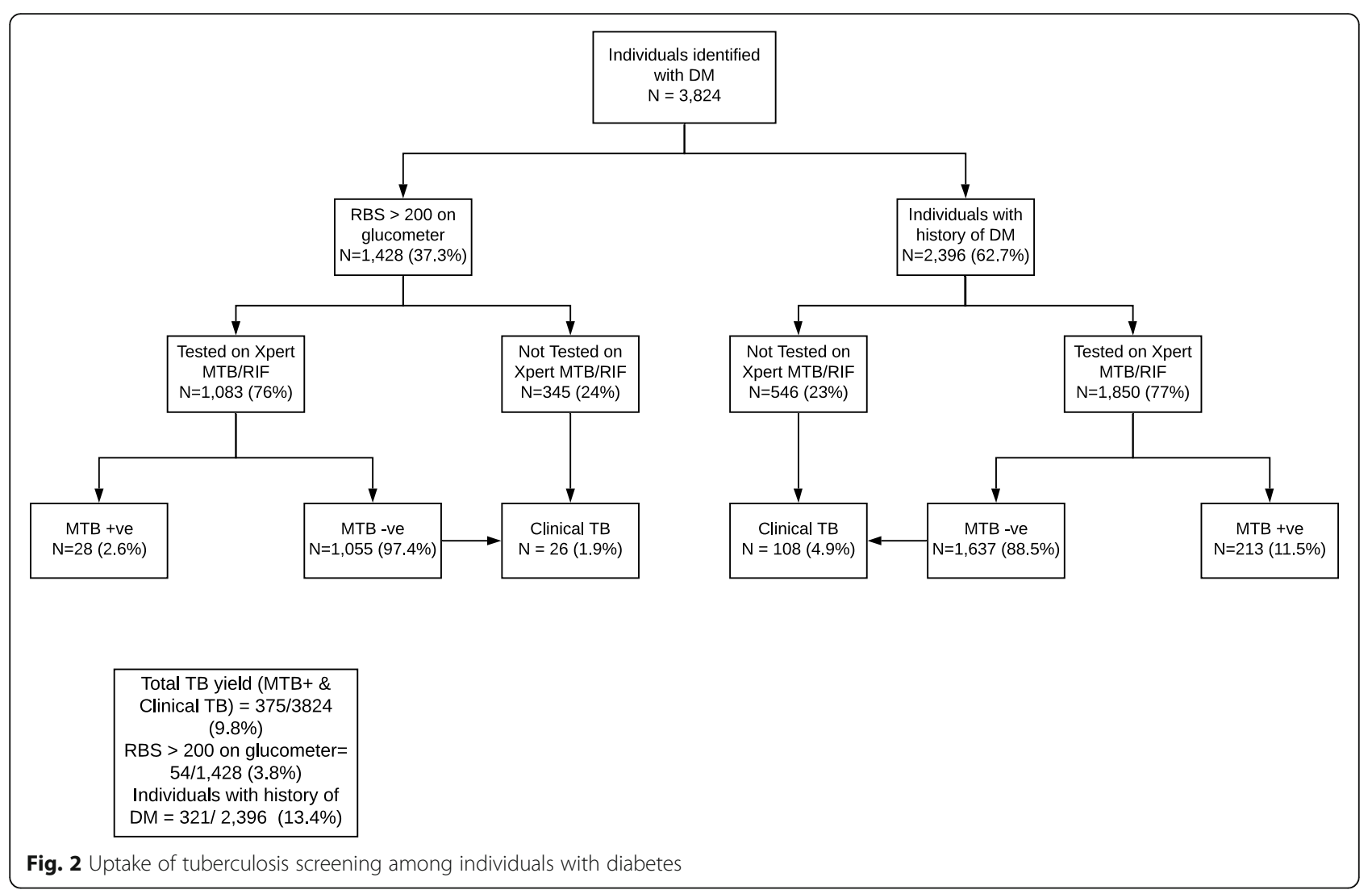

Table 2 Baseline characteristics of individuals with previously diagnosed diabetes and those identified with RBS $>200 \mathrm{mg} / \mathrm{dl}$ through screening in the private-sector in Karachi, Pakistan, from July 2016 to July 2018

\begin{tabular}{llll}
\hline & Total & RBS $>200$ & $\begin{array}{l}\text { Known case of DM } \\
\mathrm{n}(\%)\end{array}$ \\
\hline Sex & $\mathrm{n}(\%)$ & $1428(\mathbf{3 7 . 3} \%)$ & $2396(\mathbf{6 2 . 7 \% )}$ \\
Male & 3824 & $777(\mathbf{3 5 . 3} \%)$ & $1425(\mathbf{6 4 . 7 \% )}$ \\
Female & 2202 & $651(\mathbf{4 0 . 1 \% )}$ & $971(\mathbf{5 9 . 9 \% )}$
\end{tabular}

Age

$\begin{array}{llll}15-20 & 85 & 46(\mathbf{5 4 . 1 \% )} & 39(\mathbf{4 5 . 9 \% )} \\ 20-39 & 673 & 328(\mathbf{4 8 . 7 \% )} & 345(\mathbf{5 1 . 3 \% )} \\ 40-59 & 1892 & 696(\mathbf{3 6 . 8 \% )} & 1196(\mathbf{6 3 . 2 \% )} \\ >60 & 1175 & 358(\mathbf{3 0 . 5 \% )} & 817(\mathbf{6 9 . 5 \% )}\end{array}$

Source of referral

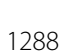

Community Camps

Others (hospitals, NGOs)

Sefl-referred

Private provider

TB diagnosis

$\begin{array}{ll}\text { No TB detected } & 3449 \\ \text { MTB + ve } & 241 \\ \text { Clinical diagnosis } & 134 \\ \text { Total TB } & 375\end{array}$

3449

375

$\begin{array}{lll}1288 & 430(\mathbf{3 3 . 4 \% )} & 858(\mathbf{6 6 . 6 \% )} \\ 331 & 108(\mathbf{3 2 . 6 \% )} & 223(\mathbf{6 7 . 4 \% )} \\ 903 & 268(\mathbf{2 9 . 7 \% )} & 635(\mathbf{7 0 . 3} \%) \\ 1302 & 622(\mathbf{4 7 . 8 \% )} & 680(\mathbf{5 2 . 2} \%)\end{array}$

1373 (39.8\%)

$28(11.6 \%)$

26 (19.4\%)

54 (14.4\%)
$<0.001$

2076 (60.2\%)

213 (88.4\%)

108 (80.6\%)

321 (85.6\%) 
Table 3 Predictors for TB detection among individuals with diabetes tested using Xpert MTB/RIF, visiting TB diagnostic and treatment centers in Karachi, Pakistan (July 2016-July 2018). Significance testing has been done using chi-squared test

\begin{tabular}{|c|c|c|c|c|c|c|}
\hline & \multicolumn{3}{|c|}{$\underline{\text { Univariate analysis }}$} & \multicolumn{3}{|c|}{$\underline{\text { Multivariate analysis }}$} \\
\hline & $\mathrm{OR}$ & $95 \% \mathrm{Cl}$ & $P$ value & $\mathrm{OR}$ & $95 \% \mathrm{Cl}$ & $P$ value \\
\hline \multicolumn{7}{|l|}{ Gender } \\
\hline Male & Ref & Ref & Ref & Ref & Ref & \\
\hline Female & 1.16 & $(0.91-1.49)$ & 0.237 & 1.21 & $(0.94-1.55)$ & 0.133 \\
\hline \multicolumn{7}{|l|}{ Age } \\
\hline Age (years) & 1.08 & $(0.92-1.26)$ & 0.343 & 0.99 & $(0.83-1.16)$ & 0.890 \\
\hline \multicolumn{7}{|l|}{ Previous History of DM } \\
\hline No previous history (RBS > 200) & Ref & Ref & Ref & Ref & Ref & \\
\hline Known case of DM & 4.58 & $(3.19-6.59)$ & 0.00 & 4.63 & $(3.21-6.66)$ & $<0.0001$ \\
\hline
\end{tabular}

time to diagnosis for $\mathrm{TB}$ of 7 years among those with DM [16].

Individuals with $\mathrm{TB}$ were screened for DM using Hbalc. The prevalence identified in our study of preDM (32\%) and DM (24\%) was much higher among individuals with $\mathrm{TB}$ than in the general population of Pakistan (17\%) [2]. This is consistent with findings from other studies that have reported a high prevalence of up to $35 \%$ of DM in TB patients [17]. The susceptibility of older individuals to TB and DM in our study is also consistent with previous studies highlighting the risk and the need for regular screening among older individuals [18-20]. HbA1c testing was repeated for subset of TB patients after 3 months of ATT. Transient hyperglycemia is a common finding among people with $\mathrm{TB}$, with HbA1c levels reverting to the euglycemic range after 3 months of TB treatment $[5,21]$. The cause of transient hyperglycemic status is likely multifactorial and due to a combination of inflammation induced by TB, the hyperglycemic effect of ATT, and individual risk of DM [21]. Transient hyperglycemia in individuals with TB makes it challenging to determine the appropriate time for screening to avoid misdiagnosis of DM. Our data suggests that screening at 3-month follow-up may be more appropriate than at ATT initiation, although further drop in Hbalc by end of ATT completion cannot be excluded. However, this needs to be balanced against the risk of potential lost to follow-up. The Union also recommends a follow-up HbA1c at treatment completion to avoid the risk of overdiagnosis of DM [6].

Our study supports the need to scale-up DM testing in existing TB programmes. An advocacy meeting facilitated by our group with stakeholders from NTP, the Diabetes Association Pakistan, the Ministry of Health and other policy makers endorsed recommendations to conduct routine screening for DM among TB patients at TB Basic Management Units (BMUs). These measures are being included as part of the National Strategic Plan for TB control in Pakistan for implementation at the district-level. Pakistan has a well-organized vertical TB program with over 1360 BMUs that provide standardized data surveillance and reporting [22]. Indicators for DM screening can feasibly be added within the existing reporting framework. Similar resources are also planned for allocation for provision of diagnostic services for public-private mix (PPM) implementing partners of the NTP, targeting the private sector.

With an estimated 19.4 million adults with DM in Pakistan, there is an important opportunity for finding undiagnosed cases of TB by incorporating TB screening within DM services [2]. Lack of awareness of the increased risk of $\mathrm{TB}$ among individuals with $\mathrm{DM}$,

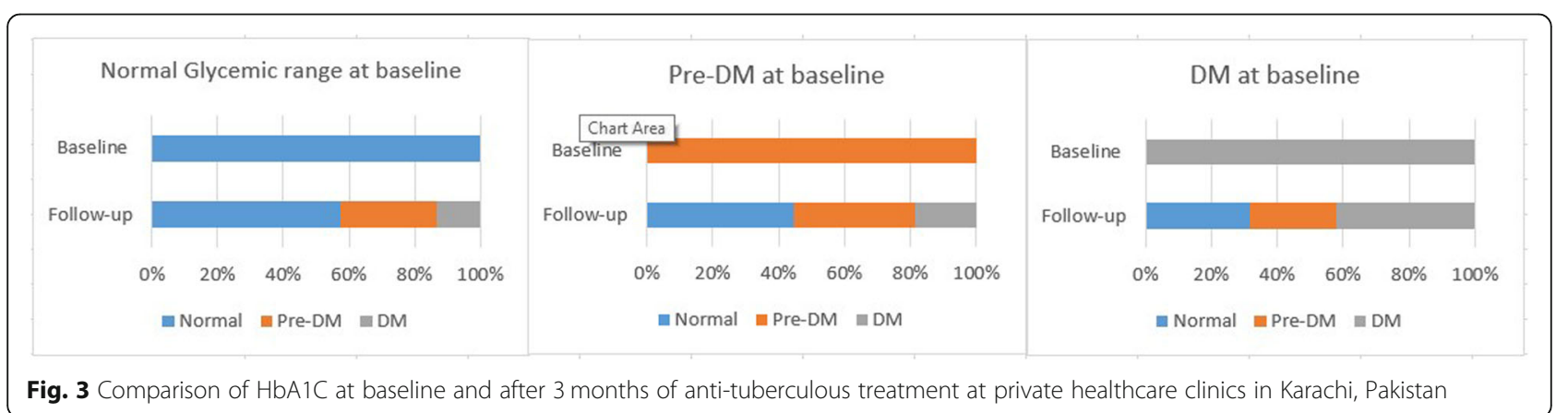


especially in the private sector needs to be therefore urgently addressed. This may be challenging, as unlike TB, there is no vertical disease program targeting noncommunicable disease (NCDs) in the country. Pakistan was one of the first low-income countries to formulate a comprehensive National Action Plan to address NCDs, but it is yet to be implemented [23]. Training, incentives for referrals and continuous engagement of privatepractitioners may facilitate TB screening in DM services. Our study supports the use of chest X-ray for TB screening in individuals with DM in high TB burden settings. While providers frequently refer patients for screening for diabetic neuropathy, diabetic nephropathy and dyslipidemia, TB could be included as an important complication of diabetes. The use of new technologies such as computer-aided detection software can facilities this process. Multi-disciplinary advocacy efforts including collaboration with diabetes professional associations and the pharmaceutical industry are required to increase awareness of TB-DM co-morbidity, combined with initiatives by NTPs to target individuals with diabetes as a high-risk group to be screened.

\section{Limitations}

It is likely that providers referred diabetics for TB screening that had symptoms of TB or had other risk factors, resulting in selection bias.

The study results may also have been confounded by other risk factors associated with $\mathrm{TB}$ among individuals with DM such as access to healthcare, level of glycemic control, compliance with DM medication as well as environmental factors such as smoking. In addition, we did not quantify the duration of DM among those screened for TB.

\section{Conclusion}

This study provides evidence for engagement of private sector in finding missing cases of TB and DM through systematic bi-directional screening approaches. Given the high prevalence of undiagnosed DM in TB patients, there is a need to scale-up the availability of DM testing and treatment services in TB facilities. A high yield for TB was identified among diabetics and pre-diabetics in our study population. There is an urgent need to address the lack of sensitization among the private providers about the risk of TB among diabetics, due to which TB cases among diabetics are frequently missed. Multidisciplinary advocacy efforts including collaboration with diabetes professional associations and the pharmaceutical industry are required to increase awareness of the TB-DM co-morbidity.

\section{Abbreviations}

TB: Tuberculosis; Xpert: Xpert MTB/RIF test; CXR: Chest X-ray;

CAD4TB: Computer Aided Detection for Tuberculosis; DM: Diabetes Mellitus;
MTB: Mycobacterium tuberculosis; RBS: Random blood sugar; ATT: Anti Tuberculous Treatment; NTP: National TB Control Program; NCD: Noncommunicable disease

\section{Acknowledgements}

We would like to dedicate this paper to the late Dr Samad Shera, President Diabetes Association of Pakistan, for his technical guidance for the project. We would also like to thank Mr. Muhammad Yasir, Mr. Pardeep Kumar, Dr. Roshan Nisar and Mr. Hamza Tariq for support in the project's field implementation and Ms Kiran Sohail for data management for the project.

\section{Authors' contributions}

SSH, SMAZ, SR were involved in conception of the study and finalizing the study design. SSH, SR, SMA and WZJ were involved in conducting data collection, the literature review, data analysis, data interpretation and drafting the manuscript. RAF, AK and SMAZ reviewed the drafts critically and finalized the manuscript. All authors reviewed and approved the final version to be published.

\section{Funding}

Establishment of the TB testing and diagnostic centers was funded by STOP TB partnership's TB Reach Initiative and UNITAID. The scale up was funded by Global Fund for Aids, TB and Malaria. World Diabetes Foundation supported the project activities. No funding was available for data analysis \& interpretation, manuscript write up and publication of this study.

\section{Availability of data and materials}

The datasets used and analysed during the current study are available from the corresponding author on reasonable request.

\section{Ethics approval and consent to participate}

An ethical approval was deemed unnecessary for this study by The Institutional Review Board (IRB) at Interactive Research and Development (IRD) under the IRB exemption category 7 under 45 CFR 46.101(b). The IRB is registered with the U.S. Department of Health and Human Services (DHHS), Office for Human Research Protections (IRB\#00005148). A Verbal consent was obtained from participants before conducting blood glucose, HbA1c and Xpert MTB/RIF tests. This study was part of a larger study (IRB approval number IRD_IRB_2016_08_001). De-identified data from the project was used for data analysis.

\section{Consent for publication}

Not applicable.

\section{Competing interests}

The authors declare they have no competing interests.

\section{Author details}

${ }^{1}$ Community Health Solutions, 9th Floor, Al-Tijarah Building, Main Shahrah-e-Faisal, Karachi, Pakistan. 'London School of Hygiene and Tropical Medicine, Keppel St, Bloomsbury, London WC1E 7HT, UK. ${ }^{3}$ Interactive Research \& Development, 4th Floor, Woodcraft Building, Plot No. 3 \& 3-A, Sector 47, Korangi Creek Road, Karachi, Pakistan.

Received: 18 December 2019 Accepted: 13 April 2020

Published online: 19 April 2020

\section{References}

1. World Health Organization. Global report on diabetes. Geneva: World Health Organization; 2016.

2. International Diabetes Federation. IDF Diabetes Atlas, 9th edn. Brussels: 2019. Available at: https://www.diabetesatlas.org.

3. Global tuberculosis report 2019. Geneva: World Health Organization; 2019. Licence: CC BY-NC-SA 3.0 IGO

4. Zheng C, Hu M, Gao F. Diabetes and pulmonary tuberculosis: a global overview with special focus on the situation in Asian countries with high TB-DM burden. Glob Health Action. 2017;10(1):1264702.

5. Gupte AN, Mave V, Meshram S, Lokhande R, Kadam D, Dharmshale S, Bharadwaj R, Kagal A, Pradhan N, Deshmukh S, Atre S. Trends in HbAlc levels and implications for diabetes screening in tuberculosis cases undergoing treatment in India. Int J Tuberc Lung Dis. 2018;22(7):800-6. 
6. Lin Y, Harries AD, Kumar AMV, Critchley JA, van Crevel R, Owiti P, Dlodlo RA Dejgaard A. Management of diabetes mellitus-tuberculosis: a guide to the essential practice. Paris: International Union Against Tuberculosis and Lung Disease; 2019.

7. The Looming Co-Epidemic Of Tb-Diabetes: A Call To Action. theunion.org/; 2014.

8. Basir MS, Habib SS, Zaidi SM, Khowaja S, Hussain H, Ferrand RA, Khan AJ Operationalization of bi-directional screening for tuberculosis and diabetes in private sector healthcare clinics in Karachi, Pakistan. BMC Health Serv Res. 2019;19(1):147.

9. World Health Organization. Collaborative framework for care and control of tuberculosis and diabetes. Geneva: World Health Organization; 2011.

10. Spatial distribution of health consultations in the past two weeks by provider type and district: Pakistan Social and Living Standards Measurement Survey 2014-15 [Internet]. Journal Of Pakistan Medical Association; 2017. Available from: https://jpma.org.pk/article-details/8325.

11. Kim HJ, Choi EY, Park EW, Cheong YS, Lee HY, Kim JH. The utility of HbA1c as a diagnostic criterion of diabetes. Korean J Fam Med. 2011;32(7):383.

12. Walker C, Unwin N. Estimates of the impact of diabetes on the incidence of pulmonary tuberculosis in different ethnic groups in England. Thorax. 2010; 65(7):578-81.

13. Stevenson CR, Forouhi NG, Roglic G, Williams BG, Lauer JA, Dye C, Unwin N. Diabetes and tuberculosis: the impact of the diabetes epidemic on tuberculosis incidence. BMC Public Health. 2007;7(1):234.

14. Ponce-de-Leon A, de Lourdes G-GM, Garcia-Sancho MC, Gomez-Perez FJ, Valdespino-Gomez IL, Olaiz-Fernandez G, Rojas R, Ferreyra-Reyes L, CanoArellano B, Bobadilla M, Small PM. Tuberculosis and diabetes in southern Mexico. Diabetes Care. 2004;27(7):1584-90.

15. Jeon CY, Murray MB. Diabetes mellitus increases the risk of active tuberculosis: a systematic review of 13 observational studies. PLoS Med. 2008:5(7):e152

16. Restrepo Bl. Diabetes and tuberculosis. InUnderstanding the host immune response against mycobacterium tuberculosis infection. Cham: Springer; 2018. p. 1-21.

17. Jeon CY, Harries AD, Baker MA, Hart JE, Kapur A, Lönnroth K, Ottmani SE, Goonesekera S, Murray MB. Bi-directional screening for tuberculosis and diabetes: a systematic review. Tropical Med Int Health. 2010;15(11):1300-14.

18. Leung CC, Lam TH, Chan WM, Yew WW, Ho KS, Leung GM, Law WS, Tam CM, Chan CK, Chang KC. Diabetic control and risk of tuberculosis: a cohort study. Am J Epidemiol. 2008;167(12):1486-94.

19. Pal R, Ansari MA, Hameed S, Fatima Z. Diabetes mellitus as hub for tuberculosis infection: A snapshot. Int J Chron Dis. 2016.

20. Byng-Maddick R, Noursadeghi M. Does tuberculosis threaten our ageing populations? BMC Infect Dis. 2016:16(1):119.

21. Boillat-Blanco N, Ramaiya KL, Mganga M, Minja LT, Bovet P, Schindler C, Von Eckardstein A, Gagneux S, Daubenberger C, Reither K, Probst-Hensch N. Transient hyperglycemia in patients with tuberculosis in Tanzania: implications for diabetes screening algorithms. J Infect Dis. 2015;213(7): 1163-72.

22. Stoptb.org. (2019). [online] Available at: http://www.stoptb.org/assets/ documents/news/Pakistan\%20National\%20TB\%20Control\%20Program\%2 OCommemorates\%20World\%20TB\%20Day\%20in\%20Style.pdf [Accessed 17 Sept. 2019]

23. NCDs POLICY BRIEF - PAKISTAN. The World Bank, South Asia Human Development, Health, Nutrition, and Population; 2011 [cited 25 November 2019]. Available from: http://siteresources.worldbank.org/SOUTHASIAEXT/ Resources/223546-1296680097256/7707437-1296680114157/NCD_PK Policy_Feb_2011.pdf.

\section{Publisher's Note}

Springer Nature remains neutral with regard to jurisdictional claims in published maps and institutional affiliations.

Ready to submit your research? Choose BMC and benefit from:

- fast, convenient online submission

- thorough peer review by experienced researchers in your field

- rapid publication on acceptance

- support for research data, including large and complex data types

- gold Open Access which fosters wider collaboration and increased citations

- maximum visibility for your research: over $100 \mathrm{M}$ website views per year

At $\mathrm{BMC}$, research is always in progress.

Learn more biomedcentral.com/submissions 